\title{
Experience of a tertiary-level urology center in the clinical urological events of rare and very rare incidence. III. Psychourological events: 2. Phobia of renal failure due to loin pain
}

\author{
Rabea Ahmed Gadelkareem ${ }^{1 *} \mathbb{D}$, Nashwa Mostafa Azoz ${ }^{2}$, Ahmed Reda' , Ahmed Abdelhamid Shahat ${ }^{1}$,

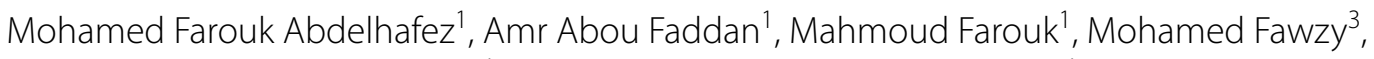 \\ Mahmoud Mohammed Osman ${ }^{1}$ and Mohammed Abdallah Elgammal ${ }^{1}$
}

\begin{abstract}
Background: End-stage renal disease and loin pain are prevalent nephrourological topics with unfavorable reputations among populations. We aimed to present our center's experience with the cases of phobia of renal failure in relation to loin pain.

Methods: It is a retrospective study of phobia of renal failure among the patients who presented with loin pain to our center between July 1991 and June 2017. Description of perception of renal failure risk was guided by the modified Common Sense Model of Illness Representation.

Results: Of more than 64,000 patients who presented with loin pain, only 78 patients $(0.12 \%)$ had phobia of renal failure. Mean age \pm SD (Range) was $41.12 \pm 9.58$ (23-60) years. Sixty-four patients (82.1\%) expressed directly fear of renal failure. Physical examination and investigations revealed no risks of renal failure in all patients. High percentages of phobia of renal failure were associated with the female gender $(73.1 \%)$, the presence of a relative patient with renal failure (83.3\%), and low socioeconomic levels: education (89.7\%), residential (75.6\%), and economic status (88.5\%) levels. The modified Common Sense Model of IIIness Representation revealed predominant emotional representations and unreal cognitive domains with altered perception of renal failure risk.

Conclusions: Phobia of renal failure is very rare. It is a consequence of the altered perception of risk of renal failure due to unconscious attribution of loin pain to renal failure. Female gender, the presence of a relative with renal failure, and low socioeconomic levels could be suggested as risk factors for phobia of renal failure.
\end{abstract}

Keywords: Disease phobia, Loin pain, Phobia, Renal failure, Renal pain, Specific phobia

\section{Background}

Phobia is one of the common anxiety disorders which has different types and mechanisms. It comes from Greek terms and means irrational fear from a certain object or situation. This fear is not shared by the consensual

\footnotetext{
${ }^{*}$ Correspondence: dr.rabeagad@yahoo.com

${ }^{1}$ Assiut Urology and Nephrology Hospital, Faculty of Medicine, Assiut University, Elgamaa Street, Assiut, Egypt

Full list of author information is available at the end of the article
}

surroundings, and it is out of proportion to the actual danger $[1,2]$. It could be encountered in the clinical practice due to an individual's altered perception of a certain disease risk such as cancer or organ failure, where it is known as disease phobia or nosophobia. The latter is defined as persistent, unjustified, and unresolved fear of having a certain disease, despite the free medical examinations and reassurances [3]. Specifically, fear of kidney disease or albuminurophobia is defined as excessive 
fear of increased albumin in urine or certain symptoms related to kidney diseases [1]. On one hand, loin pain is a cardinal complaint in the urological clinics as an upper urinary tract symptom. It has a multi-factorial etiology with significant non-urological contributors and differentials. The urological causes are mainly disorders of the kidneys and ureters such as urolithiasis [4-6]. On the other hand, chronic kidney disease (CKD), including the end-stage renal disease (ESRD), is an increasing worldwide problem $[7,8]$, may be accompanied by renal pain, and comes on top of the kidney disorders which may have an altered perception of risk among certain populations $[9,10]$. Accordingly, public awareness of the pathological and anatomical contexts of loin pain to the kidney and the increasing prevalence of ESRD may represent a psychosocial stress factor for altered perception of a disease risk. In contrast to the populations who make barriers against the access to the healthcare under denial and fear of CKD [11], other populations may express over estimation and fear of CKD without being at real risks [12].

There is a predominant research focus on the psychiatric disorders among CKD patients under the medical disciplines of psychosomatic urology and nephrology [13]. However, there is an insufficient number of researches involving the psychosocial aspects of CKD among the populations of early stages of CKD and the general populations [14-16]. The intense fear or phobia of getting CKD without being at risk is one of these aspects [17]. Owing to the noticeable social vigilance about renal safety, the current study was conducted to evaluate the magnitude and impacts of the fear of ESRD among the patients of loin pain.

\section{Methods}

A retrospective study of the patients' records in our hospital between July 1991 and June 2017 was conducted. Records of the patients who presented with loin pain and intense fear of renal failure as cardinal complaints were reviewed. Phobia of renal failure was defined as long-term (more than 6 months) complaint of irrational fear of renal failure or manifestations referring to this fear such as frequent visits to urological or nephrological care for getting assurance about the kidneys without being at a significant risk and repeating the same complaint with or without psychosomatic manifestations like generalized malaise, sweating, short breath, and chest tightness. Patient records which fulfilled this definition were assigned to have the diagnosis of phobia of renal failure. The findings of psychiatric evaluation which were reported in patients' records were surrogates to establish the diagnosis of disease phobia. This diagnosis was revised according to the fifth edition of the Diagnostic and Statistical Manual of Mental Disorders (DSM-5). The demographic variables including age, gender, and socioeconomic levels were reviewed. Also, relevant findings such as the presence of a relative or a known person who had renal failure and poor socioeconomic factors were studied as potential risk factors. Clinical characteristics were extracted from the reported findings of physical examination and basic laboratory (urine analysis and serum creatinine) and imaging (abdominal ultrasonography and radiography) investigations. Patients with recorded potential significant risks of ESRD such as acute or chronic renal impairment, a relative with hereditary ESRD, multiple urinary surgeries or nephrectomy including living kidney donation and kidney transplantation, systemic chronic diseases such as diabetes mellitus, hypertension, obesity, life-threatening comorbidities such as malignancy, and psychiatric disorders, all were excluded from the current study.

Diagnosis of the status of perception of the risk of renal failure among the patients suffering from loin pain without being at real risks was guided by the modified Common Sense Model (CSM) of Illness Representation [10]. Records of all cases were sufficient to be included in the model.

\section{Results}

Out of more than 64, 000 patients who presented with loin pain as a cardinal symptom, only 78 patients $(0.12 \%)$ met the inclusion criteria to have the diagnosis of phobia of renal failure.

Demographic and clinical characteristics were summarized in Table 1. Mean age \pm SD (Range) was $41.12 \pm 9.58$ (23-60) years. The majority of the cases $(65 \%)$ were 30-50 years old. Records of clinical examinations did not reveal relevant findings of CKD. Also, values of the basic laboratory tests including urine analysis, renal functions, and imaging were unremarkable in all cases, except in a few cases which had minimal abnormalities resulting in a very little or no risk of renal failure (Table 1).

Referral to psychiatric evaluation and management was recorded to all patients. Eighteen patients (23.1\%) refused the continuation of psychiatric management. Sixty patients $(76.9 \%)$ agreed to psychiatric referral, evaluation, and management. Of them, 13 patients (16.7\%) lost their follow up after their first psychiatric management. However, 47 patients $(60.3 \%)$ continued their management with variable follow up periods (Table 1). Sixteen patients $(20.5 \%)$ suffered from relapse attacks of phobia of renal failure.

According to CSM, all patients had an altered risk perception of renal failure as an overestimated risk. Illness stimuli and disease representation domains were demonstrated (Table 2). The current experience information 
Table 1 Demographic and clinical characteristics of patients $(n=78)$ of phobia of renal failure

\begin{tabular}{lll}
\hline Variables/characteristics $\quad$ Values & Percentages \\
\hline
\end{tabular}

Age range (Mean $\pm S D)$ in years $23-60(41.12 \pm 9.58)$

Gender

Male

Female

$21 \quad 26.9$

Marital status

single

Married

Divorced

Widow

Job

Employed

Unemployed

Education level $^{a}$

\section{None}

Low

Middle

High

Residential status

Low

Middle

High

Economic level $^{b}$

\begin{tabular}{|c|c|c|}
\hline Low & 44 & 56.4 \\
\hline Middle & 25 & 32.1 \\
\hline High & 9 & 11.5 \\
\hline \multicolumn{3}{|l|}{ Fear expression } \\
\hline Direct complaint & 64 & 82.1 \\
\hline Indirect complaint & 14 & 17.9 \\
\hline \multicolumn{3}{|l|}{ Loin pain } \\
\hline \multicolumn{3}{|l|}{ Anatomical side } \\
\hline Right & 6 & 7.7 \\
\hline Left & 10 & 12.8 \\
\hline Bilateral & 62 & 79.5 \\
\hline \multicolumn{3}{|l|}{ Character } \\
\hline Dull ache & 57 & 73.1 \\
\hline Heaviness/Discomfort & 21 & 26.9 \\
\hline $\begin{array}{l}\text { Duration (Mean } \pm \text { SD in } \\
\text { months) }\end{array}$ & $7-36(15.29 \pm 6.17)$ & \\
\hline \multicolumn{3}{|c|}{ Constitutional Symptoms of phobia } \\
\hline Headache & 59 & 75.6 \\
\hline Dyspepsia/anorexia & 48 & 61.5 \\
\hline Others $^{c}$ & 51 & 65.4 \\
\hline \multicolumn{3}{|l|}{ Clinical visits } \\
\hline Frequency (Mean \pm SD) & $4-12(7.44 \pm 2.99)$ & \\
\hline Specialties number & $2-3$ & \\
\hline \multicolumn{3}{|l|}{ Relevant history of ESRD } \\
\hline Relative HD-patient & 65 & 83.3 \\
\hline Non-relative & 13 & 16.7 \\
\hline
\end{tabular}

Table 1 (continued)

\begin{tabular}{lll}
\hline Variables/characteristics & Values & Percentages \\
\hline $\begin{array}{l}\text { Investigations } \\
\text { Urine analysis }\end{array}$ & \\
$\quad$ Albuminuria & 0 & 0 \\
$\quad$ Crystalluria & 7 & 9 \\
Serum creatinine range (mg/dl) & $0.6-1.2$ & \\
Imaging (US, KUB, IVU, CT) & & 3.8 \\
$\quad$ Simple renal cysts & 3 & 1.3 \\
Ectopic kidney & 1 & 2.6 \\
Solitary renal stone & 2 & 5.1 \\
Phleboliths & 4 & 87.2 \\
$\quad$ Normal & 68 & \\
Follow up range (years) & $5-7$ &
\end{tabular}

$S D$ standard deviation, ESRD end-stage renal disease, $H D$ hemodialysis, US ultrasonography, KUB kidney-ureter-bladder radiography film, $I V U$ intravenous urography, CT computed tomography

a Education level: Education level was categorized into: Low (essential education levels), Middle (Secondary school levels), and High (College and higher levels)

b Economic level: It considered the regular annual income

c Other constitutional symptoms include chest tightness, short breathing, lethargy, sweating, and insomnia

source was due to non-self-ESRD experience. Incorrectly formulated cognitive domains with extreme emotional illness representation resulted in irrational fear of renal failure and altered perception of risk. Coping strategies included the frequent seeking of medical consultations and trials to document the renal insults.

\section{Discussion}

Phobia is defined as the experience of an irrational fear with exposure to a certain object or situation. It may develop as a fear of getting a certain illness such as ESRD, where it is known as disease phobia. Previously, it was classified under the old term "hypochondriasis", but it should be differentiated from hypochondriasis based on specifying the fear toward a certain disease risk $[1,3]$. However, the term hypochondriasis has recently been replaced by two terms; "somatic symptom disorders" and "illness anxiety disorders" according to DSM-5. The former term refers to a fear of a disease with the presence of real physical symptoms. However, the latter term refers to a fear of developing a disease with a little of or without real symptoms [18-20]. However, disease phobia could be considered as a specific phobia according to the latest versions of DSM and on the basis of that the fear is from a future rather than from a current disease process [20]. Accordingly, we suggest to consider the fear of renal failure due to loin pain as a specific phobia rather than a somatic symptom disorder. This identification may professionally introduce this mental representation into the 
Table 2 Stimuli and representations of phobia of renal failure according to CSM

\begin{tabular}{|c|c|c|c|c|c|}
\hline \multirow[t]{14}{*}{ A: Illness stimuli } & Sources & Status & & Patients $(n=78)$ & Percentages \\
\hline & Lay information & Yes & & 78 & 100 \\
\hline & & None & & 0 & 0 \\
\hline & External information & Yes & & 78 & 100 \\
\hline & Current experience & None & & 0 & 0 \\
\hline & & Self & & 0 & 0 \\
\hline & & Known patients ${ }^{a}$ & & 78 & 100 \\
\hline & & & Father & 6 & 7.6 \\
\hline & & & Mother & 5 & 6.4 \\
\hline & & & Brother & 3 & 3.9 \\
\hline & & & Sister & 2 & 2.6 \\
\hline & & & Distant relative & 49 & 62.8 \\
\hline & & & Neighbor & 8 & 10.3 \\
\hline & & & Occupational & 5 & 6.4 \\
\hline \multirow[t]{8}{*}{ B: Illness representations } & & Levels & Domains & Clinical expressions & \\
\hline & & & & Native & Altered/Announced \\
\hline & & Cognitive & Cause & $\begin{array}{l}\text { Undetermined }(n=47) \\
\text { Non-renal }(n=31)\end{array}$ & Renal pathology \\
\hline & & & Identity & Loin pain & CKD/ESRD \\
\hline & & & Timeline & Stationary/Regressive & Chronic/Progressive \\
\hline & & & Controllability & Controllable & Non-controllable \\
\hline & & & Consequence & None or minimal & HD and death \\
\hline & & Emotional & Distress/Anxiety & None or minimal fear & Irrational fear \\
\hline
\end{tabular}

CSM the common sense model (CSM) of illness representation, CKD chronic kidney disease, ESRD end-stage renal disease, $H D$ hemodialysis

a Source of information was from an individual who was related or known to the patient and was on hemodialysis or died from renal failure

clinical practice, because phobia of renal failure may represent a marked psychiatric impact among peoples who have a relative, friend, or a neighbor with CKD or ESRD and on hemodialysis. Clinically, it presents with anxiety disorders such as irrational fear of getting renal failure where it is also known as albuminurophobia [1].

Psychosomatics in urology and nephrology are progressively growing medical disciplines that represent the interface between psychiatry and medicine within the biopsychosocial model of mind-body unity. They deal commonly with the functional symptomization due to psychological burdens such as the problems of CKD in nephrology and the somatoform urinary symptoms including syndromes of chronic genitourinary pain [13, 21,22]. Extreme fears and phobias of being diseased with renal failure represent the clinical formulation of the altered perception of CKD risk and could be conceptualized as one of the psychosomatic presentation. Because this altered perception is undermined by the socially stigmatized association between loin pain as a cardinal nephrourological symptom and CKD as a cardinal nephrourological pathology, we believed that considering phobia of renal failure as a common entity between the urological and nephrological practices under the topic of psychosomatics could be justified.
The basic sources of information of an individual's illness are three types. Firstly, the lay or general information source which depends on the cultural knowledge and social communications. Secondly, the external information source which comes from the family, friends, and health care providers. Thirdly, the source of current experiences that may come from the individual himself or his relatives who have an illness or its risk factors and from work-related exposure to illnesses [10, 23]. These sources are known as the illness stimuli and they are incorporated into the CSM [10]. Information from these sources contribute to creation of the cognitive (cause, identity, timeline, controllability, and consequences) and emotional domains of the individual's representation of a specified illness such as renal failure or formation of the sense of that illness [10, 23]. Although the cognitive illness domains influence individuals' beliefs and risk perception of diseases as a significant component of the overall disease representations, the emotional domains become important in the description of CKD representations. According to the CSM, emotional states such as fear and distress feelings could be elicited by health threats $[10,23]$. Phobia of renal failure in the current series may provide a clear example for the overwhelming role of the emotional representations in the clinical reproduction of 
the altered perception of risks of CKD and ESRD among the publics for whom there were a very little or no risk.

Perception of ESRD risks among population could be altered by sociocultural factors such as the poor residential, economic deprivations, low education level, and social stressors. This altered perception may affect the access to the health services in the form of under or over motivation. Although the issue of lower access to the healthcare services has been studied on the light of the CSM [10], the magnified altered perception of ESRD risk on the psychosocial bases seems to be not well-studied in the literature [17]. Regarding the risks of renal failure, the population of the current series had definitively no significant risks. Although the relatives of ESRD patients have been reported to have high risks to develop it due to hereditary and familial diseases [24], we included them in the current study. We relied on the exclusion of those patients who had known ESRD relatives with predetermined hereditary causes and on the absence of markers of CKD by investigations. They could be paralleled to the non-donor population in a previous comparison that was done between former living kidney donors and their mates from the general population for the perception of the risks of ESRD [17]. Paradoxically, the nondonors were found to have higher proportions of altered perception of risk relative to the donors. This finding was attributed to the extensive investigation, counseling, and reassurance of the former donors in contrast to the non-donors who lacked these work ups about their renal functions. The non-donors were affected by beliefs such as that they could be affected by the ESRD because of their gene-relatedness to ESRD patients [17].

In the recent era, emotions are considered to have integral physiological and behavioral parts accompanying the mental states or feelings. So, emotions are expressed at three different levels; psychological, physiological, and behavioral. The reaction between these levels provides a spectrum of different forms of emotions of fear starting from the protective physiological level to the psychopathological level of phobia [25]. So, phobia of renal failure due to loin pain could be conceptualized to represent a point of meeting between the medical specialties of Urology, Nephrology, and Psychopathology of emotions within the evolving medical discipline of psychosomatics [21]. This interdisciplinary conceptualization gathers these specialties in a practical framework that may enhance patients' evaluation and diagnosis.

On the other hand, loin pain is a cardinal symptom in the emergency departments and clinical urological presentations and it is associated with different renal disorders [4-6]. Also, the cultural background of the association between renal pain and renal failure represents a form of a generalized fear among publics. Many studies targeted the epidemiology and incidence of loin or flank pain and reported that the non-urological causes represent significant proportions of cases $[4,6]$.

It has been reported that the low socioeconomic standards are risk factors for CKD due to health care disparities with different mechanisms for CKD development [26]. However, in our country, these factors are predominant and their mechanisms of predisposition to CKD are possible for major proportions of the population. From the current findings, behavioral characteristics of the patients suffering from phobia of renal failure or ESRD include frequent seeking of medical visits, generalized psychosomatic complaints, and persistent trials of linking a renal disorder diagnosis to their pain. The low socioeconomic characteristics played a role in alteration of ESRD risk perception, when they were linked to loin pain. Similar forms of psychosomatic presentations of renal disorders could be found in the literature such as the loin pain hematuria syndrome and psychic anuria [12, 27]. Clinical characterization of flank or loin pain in the emergency departments according to strict guidelines or approaches seems to be heterogeneous due to the individual propensity and expertise. Also, the wide spectrum of differential diagnoses increases the complexity of loin pain. It has been classified into urgent pain that needs treatment within $24 \mathrm{~h}$ and non-urgent pain that could be managed electively $[6,28]$. In the current study, all the patients could be classified to have non-urgent loin pain. The acuteness of symptoms among those patients was shifted from loin pain toward the emotional aspect of presentation as a strong fear of getting renal failure.

Based on the modified CSM, Migliore et al. [10] studied the altered risk perception of renal disease among the African American population and found it low. In the current study, however, the overwhelming renal illness stimuli in the context of low cognitive representations potentiated the emotional representations and contributed to a paradoxical form of disease risk perception to a degree that fulfilled the definition of disease phobia. Application of the modified CSM to the population of the current study revealed significant values, where the illness stimuli were non-personal current experiences of renal failure. Emotional representations of fear were reliable more than the cognitive domains. Accordingly, modified CSM could be used as a guide for diagnosis of phobia of renal failure. Also, the exaggerated perception of risk was diagnosed by CSM and could be added to the definition of phobia of renal failure to include the followings: the general definition of phobia as irrational fear of renal failure, absence of real risks of CKD with altered perception, and the exaggerated emotional domains in disease representation. 
The issue of disease phobia in the urological practice may warrant a focused research. National and multicenter studies of the psychosomatic nephrourological disorders are recommended as much as possible the incidence of these disorders allows.

Despite the favorability of retrospective methods to the rare events, retrospective nature of the current study was the main limiting factor and resulted in inability to apply standardized psychometric tools for diagnosis of disease phobia and its differentiation from hypochondriasis and somatic symptom disorders. Also, comparative analytical studying was not possible.

\section{Conclusions}

Phobia of renal failure is a very rare disease phobia and is a consequence of altered perception of renal failure risk among publics on the basis of prevalent associated topics of loin pain and renal failure. Female gender, the presence of relative patients of renal failure, and low socioeconomic levels could be suggested as risk factors for phobia of renal failure. The modified CSM could be used as a guide for determination of disease representation and risk perception.

\section{Abbreviations}

CKD: chronic kidney disease; CSM: the common sense model of illness representation; DSM-5: the fifth edition of the diagnostic and statistical manual of mental disorders; ESRD: end-stage renal disease.

\section{Acknowledgements \\ Not applicable.}

\section{Authors' contributions}

Dr. RAG developed the concept of the manuscript and contributed to drafting, writing, and submission. Dr. NMA contributed to design, writing and revision. Dr. MFA contributed to design, writing and revision. Dr. AR contributed to data collection, writing, and revision. Dr. AAS contributed to data collection, statistical studying, writing and revision. Dr. MaF contributed to data collection, statistical studying, and revision. Dr. AAF contributed to data collection, writing, and revision. Dr. MoF contributed to writing in consideration to the psychological aspects and revision. Dr. MMO contributed to writing, statistical studying, supervision, and revision. Prof. MAE contributed to writing, supervision, and revision. All authors read and approved the final manuscript and revisions for submission. All authors agreed to be personally accountable for their own contributions and ensure that questions related to the accuracy or integrity of any part of the work, even ones in which they were not personally involved, are appropriately investigated, resolved, and the resolution documented in the literature. All authors read and approved the final manuscript.

\section{Funding}

This study received no funding from any source.

\section{Availability of data and materials}

All data generated or analyzed during this study are included in this article.

\section{Competing interests}

The authors declare that they have no competing interests.

\section{Ethics approval and consent to participate}

This study was approved within the frame of the project "Experience of a Tertiary-Level Urology Center in the Clinical Urological Events of Rare and Very Rare Incidence" by the Ethical Committee of the Faculty of Medicine, Assiut University, Egypt. Reference approval number is not applicable. Also, it is a retrospective case series study with inclusive written patients' consent to participate in academic research work, where all patients give this written consent on admission in our university hospital with full ethical considerations.

\section{Consent for publication}

Not applicable.

\section{Author details}

${ }^{1}$ Assiut Urology and Nephrology Hospital, Faculty of Medicine, Assiut University, Elgamaa Street, Assiut, Egypt. ${ }^{2}$ Nephrology Unit-Department of Internal Medicine, Assiut University Hospital, Faculty of Medicine, Assiut University, Assiut, Egypt. ${ }^{3}$ Department of Neurology and Psychiatry, Assiut University Hospital, Faculty of Medicine, Assiut University, Assiut, Egypt.

Received: 9 January 2020 Accepted: 17 June 2020

Published online: 06 August 2020

\section{References}

1. Robertson JG (ed.) (2003) An excess of phobias and manias. Senior Scribe Publications, Los Angeles, USA. https://books.google.com.eg/books ?isbn=096309193X. Accessed 7 Dec 2018

2. Rudaz M, Ledermann T, Margraf J, Becker ES, Craske MG (2017) The moderating role of avoidance behavior on anxiety over time: is there a difference between social anxiety disorder and specific phobia? PLoS ONE 12:e0180298. https://doi.org/10.1371/journal.pone.0180298

3. Sirri L, Grandi S (2012) Illness behavior. Adv Psychosom Med 32:160-181. https://doi.org/10.1159/000330015

4. Cyrus S, Etaati K (2015) Evaluating the frequency of urological causes of flank pain in adult patients that refer to urology ward in Shahid Motahari Hospital (Marvdasht, Iran) during 2013-2014. IOSR J Dental Med Sci 14:76-85. https://doi.org/10.9790/0853-14357685

5. Shokeir AA (2002) Renal colic: new concepts related to pathophysiology, diagnosis and treatment. Curr Opin Urol 12:263-269. https://doi. org/10.1159/000052446

6. Kim ST, Hwang Y, Park SC, Lee JW (2018) Epidemiology and outcomes of acute flank pain in university-affiliated regional emergency medical centers. Urogenit Tract Infect 13:14-20. https://doi.org/10.14777/ uti.2018.13.1.14

7. De Broe ME, Gharbi MB, Zamd M, Elseviers M (2017) Why overestimate or underestimate chronic kidney disease when correct estimation is possible? Nephrol Dial Transpl 32:ii136-ii141. https://doi.org/10.1093/ndt/ gfw 267

8. Kidney Disease: Improving Global Outcomes (KDIGO) CKD Work Group (2013) KDIGO 2012 clinical practice guideline for the evaluation and management of chronic kidney disease. Kidney Int 3:19-62

9. Williams A, Manias E (2008) A structured literature review of pain assessment and management of patients with chronic kidney disease. J Clinl Nurs 17:69-81. https://doi.org/10.1111/j.1365-2702.2007.01994.x

10. Migliore C, Barroso J, Vorderstrasse A (2016) Perceptions of renal disease risk among African Americans: a review of the literature. J Health Disp Res Pract 9:1-28

11. Kazley AS, Johnson EE, Simpson KN, Chavin KD, Baliga P (2014) Health care provider perception of chronic kidney disease: knowledge and behavior among African American patients. BMC Nephrol 15:112. https:// doi.org/10.1186/1471-2369-15-112

12. Bass CM, Parrott H, Jack T, Baranowski A, Neild GH (2007) Severe unexplained loin pain (loin pain haematuria syndrome): management and long-term outcome. Qatar J Med 100:369-381. https://doi.org/10.1093/ qjmed/hcm034

13. Ohtake Y (2017) Psychonephrology in Japan. Ren Replace Ther 3:25. https ://doi.org/10.1186/s41100-017-0106-y

14. Jennette CE, Vupputuri S, Hogan SL, Shoham DA, Falk RJ, Harward DH (2010) Community perspectives on kidney disease and health promotion from at-risk populations in rural North Carolina, USA. Rural Remote Health 
10:1388. Available from: www.rrh.org.au/journal/article/1388. Accessed 15 June 2019

15. McKercher C, Sanderson K, Jose MD (2013) Psychosocial factors in adults with chronic kidney disease: characteristics of pilot participants in the Tasmanian Chronic Kidney Disease study. BMC Nephrol 14:83. https://doi. org/10.1111/nep.12138

16. Lee Y, Kim MS, Cho S, Kim SR (2013) Association of depression and anxiety with reduced quality of life in patients with predialysis chronic kidney disease. Int J Clin Pract 67:363-368. https://doi.org/10.1111/ijcp.12020

17. Rodrigue JR, Fleishman A, Vishnevsky T et al (2014) Development and validation of a questionnaire to assess fear of kidney failure following living donation. Transpl Int 27:570-575. https://doi.org/10.1111/tri.12299

18. Mobley D, Baum NH, Beattie A, Nemeroff C (2019) When imagination becomes a disease: dealing with hypochondriacal patients in clinical practice. Ochsner J 19:70-73. https://doi.org/10.31486/toj.18.0123

19. American Psychiatric Association (2013) Diagnostic and Statistical Manual of Mental Disorders. Fifth Edition, American Psychiatric Publishing, Washington, D.C., USA. https://doi.org/10.1176/appi.books.9780890425596. Accessed 10 Aug 2019

20. Center for Behavioral Health Statistics and Quality (2016) Impact of the DSM-IV to DSM-5 Changes on the National Survey on Drug Use and Health. Substance Abuse and Mental Health Services Administration, Rockville, MD, USA. https://www.ncbi.nlm.nih.gov/books/NBK519704/ table/ch3.t11/. Accessed on 13 Aug 2019

21. Lee YF, Ho PS, Liang CS (2018) Brain-bladder axis: a case of anxietyassociated haematuria. Psychiat Clin Psych 28:349-351. https://doi. org/10.1080/24750573.2018.1471818
22. Noll-Hussong M, Autenrieth M, Pokorny D, Herberger S, Huber D (2012) The subject, its biology, and the chronic recurrent cystitis. Case Rep Psychiatry 2012:601705. https://doi.org/10.1155/2012/601705

23. Hagger MS, Orbell S (2003) A meta-analytic review of the Common-sense Model of Illness Representation. Psychol Health 18:141-184. https://doi. org/10.1080/088704403100081321

24. Dutta PK, Haider M, Kashem A (2015) Impaired renal function in relatives of chronic kidney disease patients. Ann Trop Med Public Health 8:113-116

25. Stiemer T (2002) The biology of fear- and anxiety-related behaviors. Dialogues Clin Neurosci 4:231-249

26. Robles-Osorio ML, Sabath E (2016) Social disparities, risk factors and chronic kidney disease. Nefrologia 36:577-579. https://doi.org/10.1016/j. nefro.2016.03.007

27. Gadelkareem RA, Moeen AM, Reda A et al (2018) Experience of a tertiarylevel urology center in the clinical urological events of rare and very rare incidence. III. Psychourological events: 1. Psychic anuria. Urol Int 101:80-84. https://doi.org/10.1159/000488881

28. Gans SL, Pols MA, Stoker J, Boermeester MA (2015) Expert steering group. Guideline for the diagnostic pathway in patients with acute abdominal pain. Dig Surg 32:23-31. https://doi.org/10.1159/000371583

\section{Publisher's Note}

Springer Nature remains neutral with regard to jurisdictional claims in published maps and institutional affiliations.

\section{Submit your manuscript to a SpringerOpen ${ }^{\circ}$ journal and benefit from:}

- Convenient online submission

- Rigorous peer review

- Open access: articles freely available online

- High visibility within the field

- Retaining the copyright to your article

Submit your next manuscript at $\boldsymbol{\nabla}$ springeropen.com 